\title{
Analysis and Design of Plastic Mold for Male Insulator of Solar Connector using Plastic Advisor 7.0
}

\author{
Lokeswar Patnaik $^{1}$ and Sunil Kumar ${ }^{2}$ \\ ${ }^{1}$ CVR College of Engineering Mechanical Department, Hyderabad, India \\ Email: lokeswar.patnaik@cvr.ac.in \\ ${ }^{2}$ CVR College of Engineering/Mechanical Department, Hyderabad, India \\ Email: sunilou13@gmail.com
}

\begin{abstract}
The intricacies in plastic mold design are accommodated by precise and correct methodology in design steps and taking into considerations the right factors. In this paper a two plate finger cam actuated injection mold is designed for a component namely 'male insulator of solar connector', the material selected for it is Poly Phenylene Oxide (Noryl-PPO). The male insulator component has intricate projections on its surface and has a threaded brass insert as well. The 3-D model of the component and extraction of core and cavities was performed in Plastic Advisor 7.0. Plastic advisor software is a powerful simulation tool to locate gate location and predict the defects in the component.
\end{abstract}

Index Terms-Mold design, Male Insulator, Solar Connector, Plastic advisor 7.0

\section{INTRODUCTION}

Injection molding is an ideal plastic manufacturing process. Due to its ability to manufacture complex plastic parts with high precision and production rates at low operation costs only a relatively high initial investment for mold design and fabrication [1]. The molding may cause defects and its processing offers a challenge during its development phase. The cost of the mold is high and any process that is not optimized renders heavy overheads during its development cycle and production. So, designing the mold which ensures best suitability for the features on the component with smooth flow of molten plastic is the demand of plastic industry [2].

Solar insulators are single contact electrical connectors commonly used in solar connectors. It consists of a plug and socket design. The plugs and sockets are placed inside a plastic shell that appears to be the opposite gender- the plug is inside a cylindrical shell that looks like a female connector but is referred to as male and the socket is inside a square probe that looks male but is electrically a female. The female connector has two plastic fingers that have to be pressed towards the central probe slightly to insert into holes in the front of the male connector. When the two are pushed together, the fingers slide down the holes until they reach a notch cut into the side of the male connector, where they pop outward to lock the two together. The male insulator consists of threaded insert of brass which is placed inside the die and then the molten plastic is introduced into the impression inside the mold.
Materials cooled to get desired form. Injection molding process can be divided into four stages which are Plasticizing, injection, packing and cooling [3]. The operations are to be carried out precisely. The tool is clamped together under high loads and is subjected to high injection pressures and high heat levels from the incoming polymer. During the cooling cycle, the mold is cooled until it reaches ejection temperature. All these factors combine to make the mold tool highly stress dynamic heat exchanger.

It is important, therefore, to ensure that the mold design takes all factors into consideration. Additionally, there are several other requirements that are needed to be considered, among which are the type of tool needed, e.g. two-plate, side core, spilt, three-plate, hot runner. And the mold material, the cavity construction, the required tool life and temperature control.

In addition to runners and gates, there are many other design issues that must be considered in the design of plastic molds. Firstly, the flow must allow the molten plastic to flow easily into all the cavities. The removal of solidified part from the mold is also equally important, so a draft angle must be applied to the mold walls. The design of the mold must also accommodate any complex features on the part such as undercuts or threads which will require additional mold pieces. Most of these devices slides into the part of the cavity through the side of the mold, and are therefore known as sliders or side-actions.

\section{Process Variables And Machine Specifications AND COMPONENT DETALLS}

\section{A. Speed related process variables}

The process variables related to speed are mold opening and closing speed, injection speed, screw rotation speed, component retracting speed.

\section{B. Pressure related process variables}

The process variables related to speed are injection pressure, holding pressure and hydraulic jack pressure.

\section{Temperature related process variables}

The process variables related to temperatures are melt temperature and cooling water temperature. 


\section{Time related process variables}

The process variables related to time are injection time, holding pressure time, pause (dwell) time, cooling time and cycle time.

The extent of variability encountered is a good indicator of the level of inherent stability present within the molding process. Hence, the smaller the variation, the more consistent and stable is the process.

The given molding machine is HMT $80 \mathrm{~T}$ machine (Toggle series), the clamping unit and injection unit specifications are shown in Table 1 and table 2 respectively.

TABLE I.

Clamping UNIT

\begin{tabular}{|l|l|}
\hline Clamp force & 80 Tons \\
\hline Distance between the tie bars & $330 \mathrm{~mm} \times 330 \mathrm{~mm}$ \\
\hline Size of the platen & $485 \mathrm{~mm} \times 485 \mathrm{~mm}$ \\
\hline Clamp stroke & $345 \mathrm{~mm}$ \\
\hline Mold height & $80 \mathrm{~mm}$ to $350 \mathrm{~mm}$ \\
\hline Ejector stroke & $110 \mathrm{~mm}$ \\
\hline
\end{tabular}

TABLE II.

INJECTION UNT

\begin{tabular}{|l|l|}
\hline Screw diameter & $28 \mathrm{~mm}$ \\
\hline Shot weight & $96 \mathrm{gm}$ \\
\hline Theoretical shot volume & $108 \mathrm{~cm}^{3}$ \\
\hline Maximum injection pressure & $2670 \mathrm{~kg} / \mathrm{cm}^{2}$ \\
\hline Injection rate & $55.2 \mathrm{~cm} / \mathrm{s}$ \\
\hline Plasticizing capacity & $20.8 \mathrm{gm} / \mathrm{s}$ \\
\hline Screw rotation & $253 \mathrm{rmm}$ \\
\hline
\end{tabular}

In injection molding, cost and complexity of the mold increases as the criticality of the produced part increases. For this male insulator to avoid more complexity split cavity, mold with finger cam actuated ejection system is preferred.

The objectives of this research are to achieve maximum production by checking flow analysis results, injection pressure, fill time analysis, confidence of fill, temperature variance and weld lines etc. before manufacturing.

TABLE III

COMPONENT DETAILS

\begin{tabular}{|l|l|}
\hline Material & $\begin{array}{l}\text { Noryl (PPO- Poly Phenylene } \\
\text { Oxide) }\end{array}$ \\
\hline Density & $1.06 \mathrm{~g} \cdot \mathrm{cm}^{3}$ \\
\hline Specific heat & $1.47 \mathrm{kj} / \mathrm{kg}^{\circ} \mathrm{C}$ \\
\hline Melting temperature & $250-300{ }^{\circ} \mathrm{C}$ \\
\hline Shrinkage & $0.005-0.01 \mathrm{~m} / \mathrm{m}$ \\
\hline Tensile strength & $55-65 \mathrm{MPa}$ \\
\hline Compressive strength of thermal & $91 \mathrm{MPa}(13.200 \mathrm{psi})$ \\
\hline $\begin{array}{l}\text { Coefficient of } \\
\text { expansion }\end{array}$ & $60 \times 10^{-6} \mathrm{~K}^{-1}$ \\
\hline Thermal conductivity & $0.22 \mathrm{~W}^{-1} \mathrm{~m}^{-1} \mathrm{~K}^{-1}$ at $23^{\circ} \mathrm{C}$ \\
\hline Thermal diffusivity & $0.14 \mathrm{~m}^{2} / \mathrm{s}$ \\
\hline
\end{tabular}

The component details are shown in table 3. The 3D model and 2D drawing are shown in figure 1 and figure $2 \mathrm{a}$ and figure $2 \mathrm{~b}$ respectively.

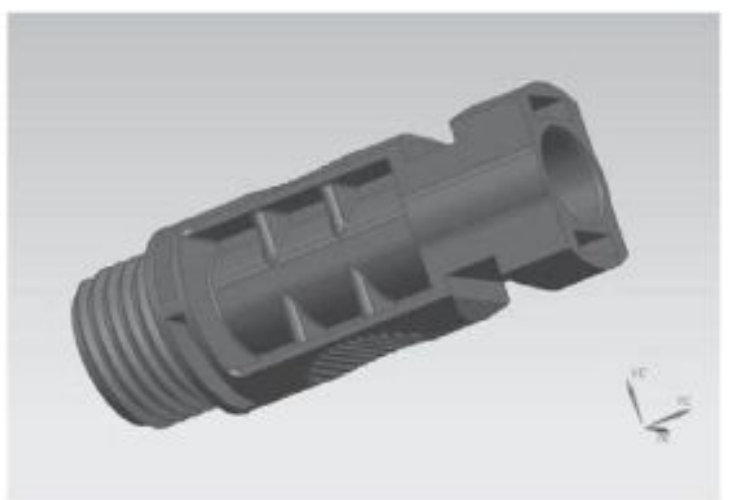

Figure 1. 3D model of male insulator of solar connector
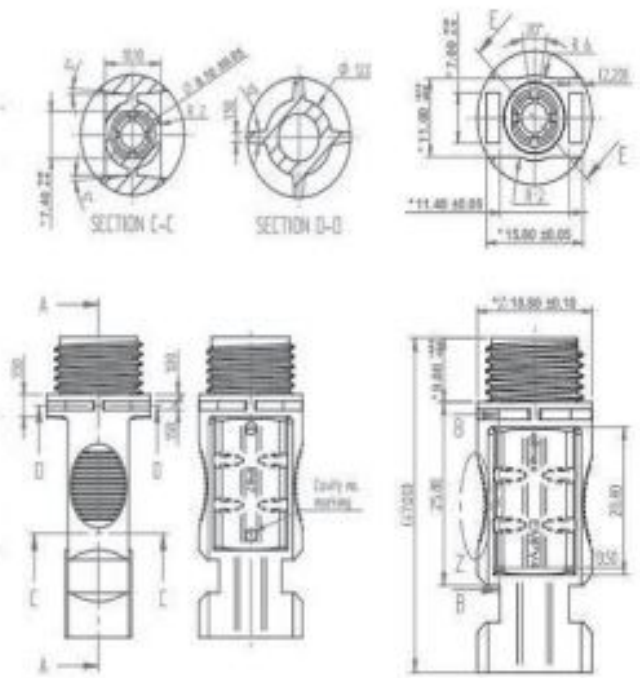

Figure 2a. 2 dimensional details of the component (male insulator)

Software is used to evaluate the mold design to make sure it will produce the most consistent and highest quality parts from each cavity of the tool. It uncovers the weakness of the dimensional geometry of the product and also it improves manufacturability.

In doing mold flow analysis, maximum production cycle time can be reduced, reduction in tooling and machining cost.

Also checking of the overall component before product design and therefore able to optimize the design process can be done. 


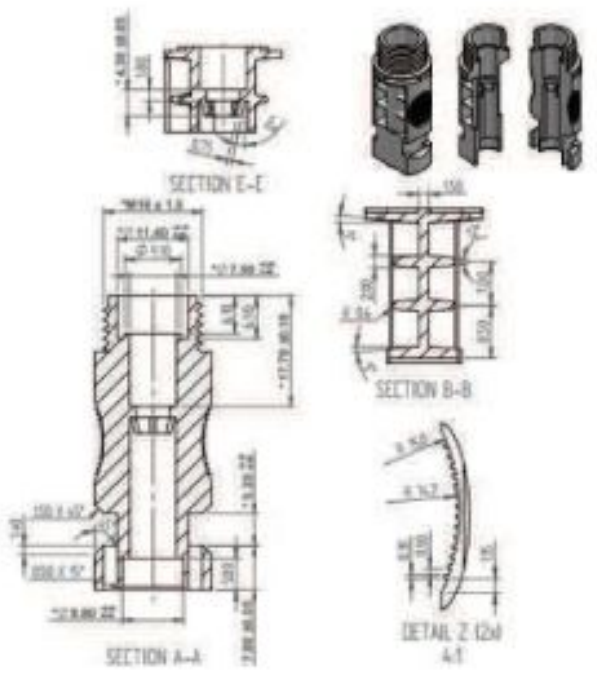

Figure 2b. 2D dimensional details of the component (male insulator)

\section{SimULATION}

The simulations are performed in Plastic advisor 7.0 which is a powerful tool to simulate the best gate location, confidence in fill, fill time, determining weld lines and air traps.

\section{A. Selection of best gate}

The result of the best gate location is obtained by Plastic advisor 7.0 and is shown in figure 3 .

In this simulation, dark blue portions shows best gate location and as the colour changes from dark blue to red, the gate location becomes worst.

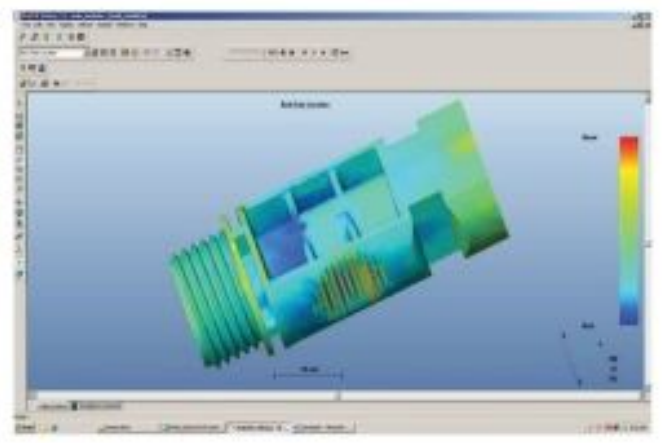

Figure 3. Result of best gate location

\section{B. Confidence of fill}

Confidence of fill depicts the reach of the molten plastic into all the intricate portion of the cavity. Confidence of fill is essential for instilling strength in the component. The result of confidence of fill is shown in figure 4 .

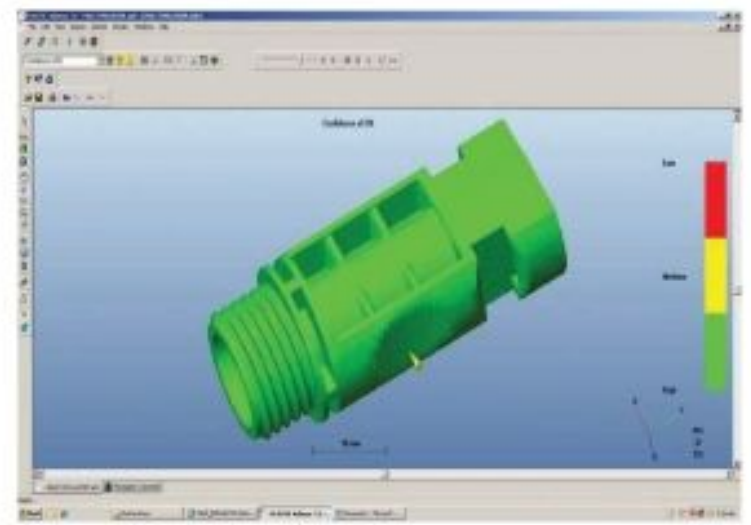

Figure 4. Result of confidence of fill

\section{Confidence of fill in two cavities with runner system}

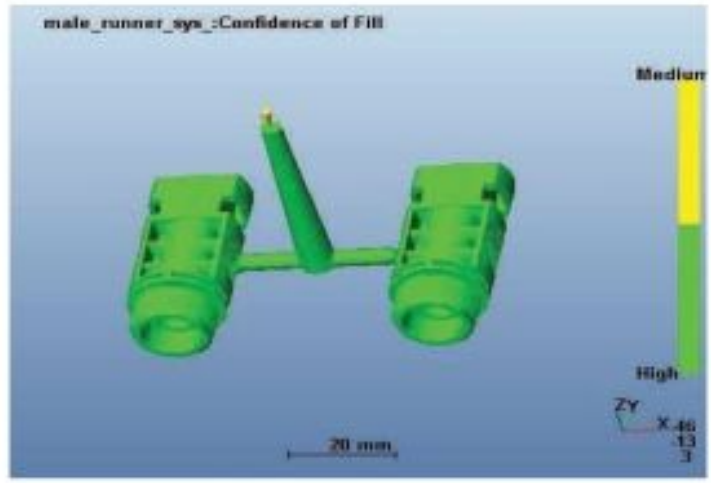

Figure 5 . Confidence of fill in two cavity with runner system.

Filling pattern plays an important role in determining and identifying any potential aesthetic issues such as short shot, air traps and weld line due to wrong location of gate [4].

The confidence of fill when the cavities are increased to two along with the runner system is shown in figure 5.

\section{Fill time}

Fill time indicates the time the molten metal is taking to fill the cavity, it affects the amount of sheer heating at surface and thinning the plastic is experiencing thus affecting the material viscosity, the pressure inside the cavity and overall part quality.

Fill time dictates the effective solidification of the plastic component, poor solidification leads to poor structure of the plastic component. The result of the simulation for fill time is shown in figure 6 . 


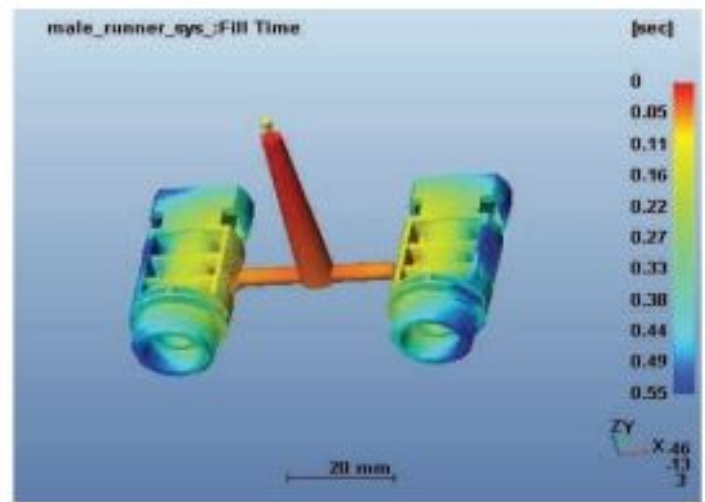

Figure 6. Result of fill time

\section{E. Pressure drop}

Pressure drop facilitates the quality of the structure of the component as well as quicker solidification and removal of the component from the mold.

The result of simulation for pressure drop is shown in figure 7.

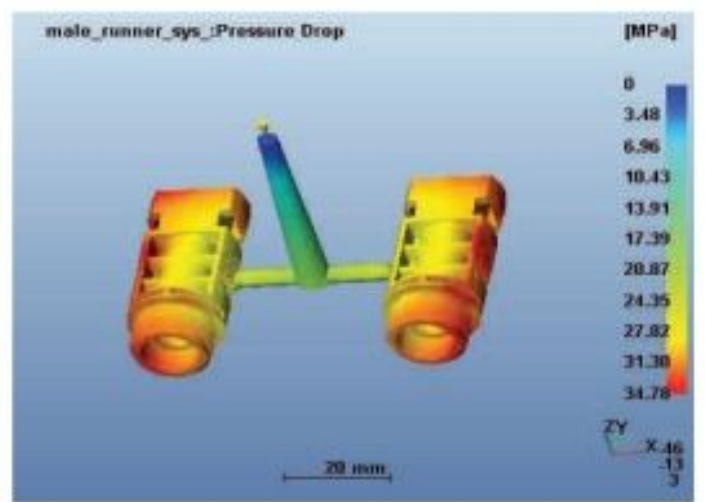

Figure 7. Result of pressure drop

\section{F. Flow front temperature}

Flow front temperature is the temperature at which shows the temperature of the polymer when the flow front reaches a specified point in the center of the plastic cross section.

It also facilitates uniform flow ability and uniform shrinkage, weld lines, hesitations, flow mark and material degradation due to high temperature in the component. The result for flow front temperature is shown in figure 8 .

The flow front temperature should not drop more than $3^{\circ}$ to $5^{\circ}$. While doing the simulation it looks for hot spots, cold spots or check where the material is excessively cooling or heating

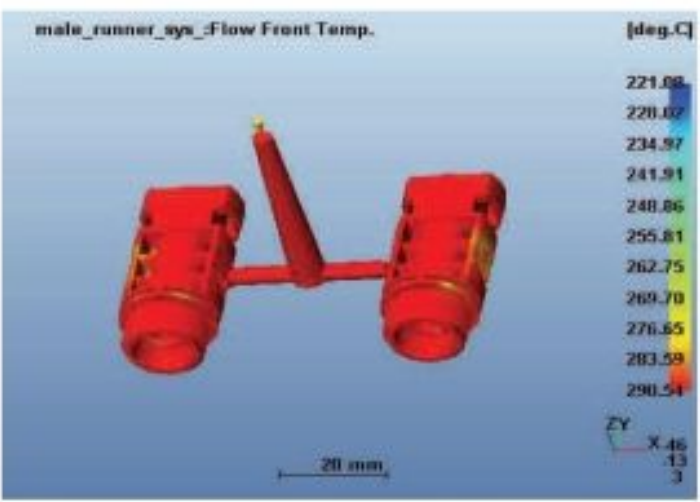

Figure 8. Result of flow front temperature

\section{G. Cooling quality}

The cooling quality has to be uniform throughout the component. The result of cooling quality is shown in figure 9.

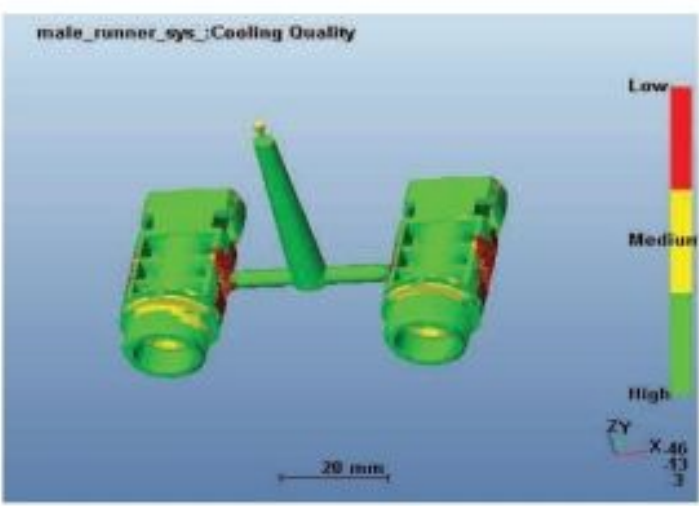

Figure 9. Result of cooling quality

\section{H.Quality prediction}

The quality of the component can be predicted using mold flow analysis. The result of quality prediction is shown in figure 10.

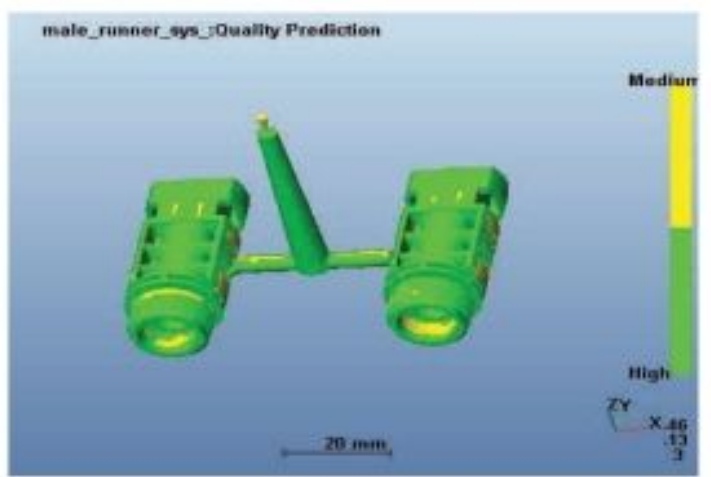

Figure 10. Result of quality prediction 


\section{Weld lines}

Weld lines are formed when the flow waves of molten plastic merges with each other. It is undesirable and prominently visible on the component.

The result of weld line formation is shown in figure 11.

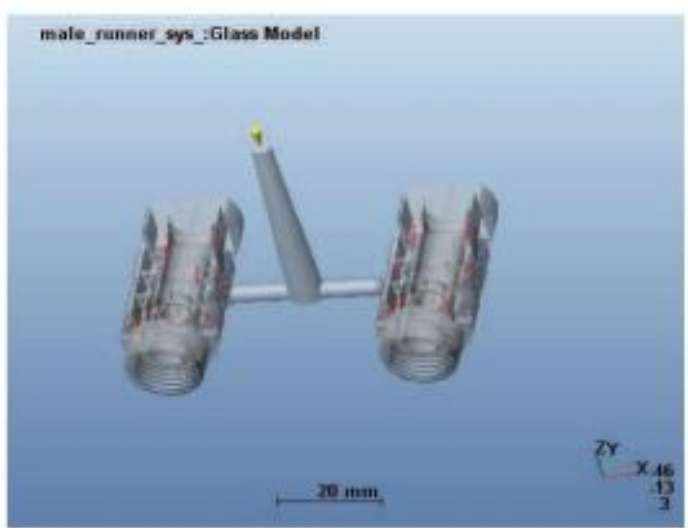

Figure 11. Result of weld line formation

\section{J. Air traps}

Air traps causes blow holes in the component thus decreasing the quality and strength of the component. It is highly undesirable and it has to be taken care beforehand itself so that once the production starts there should not be any design modification. The result of air traps in the component is shown in figure 12 .

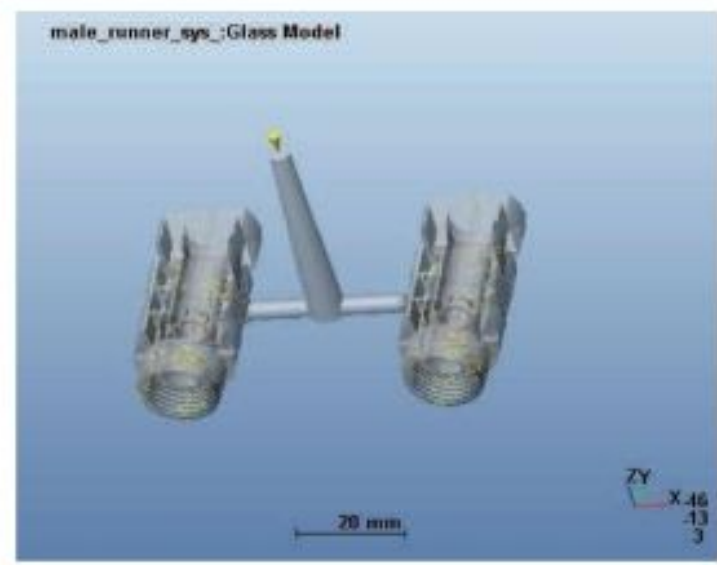

Figure 12. Result of air trap in the component

Air traps also causes blemishing on the component and difficulties in ejection of the component. Proper venting and changing the process parameter in speed and pressure are done to control it.
TABLE IV.

SUMMARY OF MOLD FLOW ANALYSIS

\begin{tabular}{|l|l|}
\hline Confidence of fill & \\
\hline Injection time & $0.55 \mathrm{~s}$ \\
\hline Injection pressure & $34.78 \mathrm{MPa}$ \\
\hline Weld lines & Partial \\
\hline Air traps & Partial \\
\hline Shot volume & $10.90 \mathrm{~cm}^{3}$ \\
\hline Quality & Good \\
\hline Filling clamp force & $2.95 \mathrm{~T}$ \\
\hline Packing clamp force estimate $@ 20 \%$ & $1.88 \mathrm{~T}$ \\
\hline Packing clamping force estimate $(980 \%$ & $7.51 \mathrm{~T}$ \\
\hline Packing clamping force $(a 120 \%$ & $11.26 \mathrm{~T}$ \\
\hline Clamp force area & $26.47 \mathrm{sq} \mathrm{cm}$ \\
\hline Cycle time & $8.78 \mathrm{~s}$ \\
\hline Surface temperature variance range & $-7.57^{\circ} \mathrm{C}$ to $9.25{ }^{\circ} \mathrm{C}$ \\
\hline Freeze time variance range & 2.168 to $5.61 \mathrm{~s}$ \\
\hline
\end{tabular}

The results obtained from mold flow analysis is very good although weld lines and air traps are present in the analysis, they can be avoided by changing the molding parameters at the time of production. The summary of the simulation is shown in table 4 .

All the results obtained are acceptable hence the design process can be started.

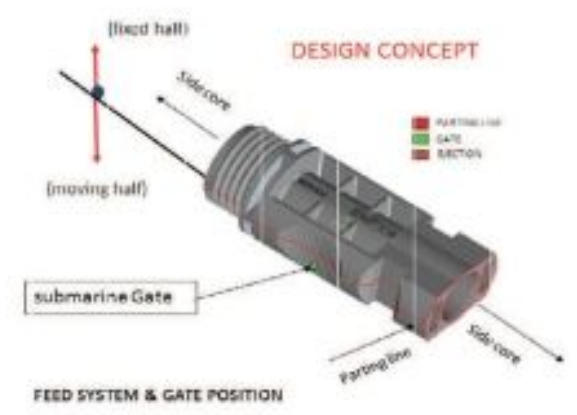

Figure 13, Design concept for male insulator

\section{K. Feed system calculations}

The maximum diameter of the sprue bushing should be greater than the nozzle orifice by $0.5-1.0 \mathrm{~mm}$. The length of the sprue channel should be as short as possible and never be over $100 \mathrm{~mm}$. The sprue included angle has to be $4^{\circ}-5^{\circ}$. The diameter of the runner is calculated by equation $1[5]$.

Runner diameter, $\mathrm{D}=\sqrt{W} \times \sqrt[4]{L} / 3.7$

Where, $\mathrm{W}=$ Weight of the component $\mathrm{L}=$ length of the runner

$\mathrm{D}=\sqrt{10.8} \times \sqrt[4]{34.2} / 3.7$

$=2.15 \mathrm{~mm}$

L. Shot weight

Shot Weight $=$ Weight of the component + Weight of the feed system 
Weight of the component $=5.4+5.4=10.8 \mathrm{gm}$

Weight of the feed system $=10 \%$ of molding $=0.54 \mathrm{gm}$

Therefore, shot weight $=10.8+0.54=11.34 \mathrm{gm}$

M.Clamping force or tonnage calculation

The clamping force calculation is shown in equation 2 [5].

Clamping force $=$ Projected area of the molding $\left(\mathrm{cm}^{2}\right) \times 1 / 3$ times of Injection pressure $\left(\mathrm{kg} / \mathrm{cm}^{2}\right)$

Injection pressure $=2670 \mathrm{~kg} / \mathrm{cm}^{2}$

Clamping force $=(8.18 \times 2670) / 1000=21.84 \mathrm{~T}$

\section{N. Working length of finger cam}

Finger cam has the advantage of easy handling and smooth opening and closing of die. It is shown in figure 14. The length of the finger cam invariably depends on the size of the component and mold, it is calculated in equation 3 [6].

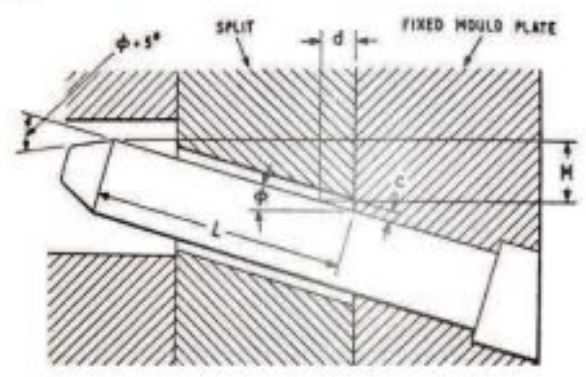

Figure 14. Finger can actuator

Working length, $L=(M / \sin \Phi)+(2 \mathrm{c} / \sin \Phi)$

Where,

$\mathrm{M}=$ Spilt movement $=27.39 \mathrm{~mm}$

$\Phi=$ Angle of finger cam $=15^{\circ}$

$\mathrm{c}=$ Clearance $=0.5 \mathrm{~mm}$

$\mathrm{L}=\left(27.39 / \sin 15^{\circ}\right) \times\left(2 \times 0.5 / \sin 15^{\circ}\right)$

$=107.83 \mathrm{~mm}$

\section{O. Cooling system}

Serial cooling channel system has been adopted for this mold for better cooling quality. For this, cooling holes of $6.0 \mathrm{~mm}$ diameter with $1 / 8 \mathrm{BSP}$ (British standard pipe) plugs have been made.

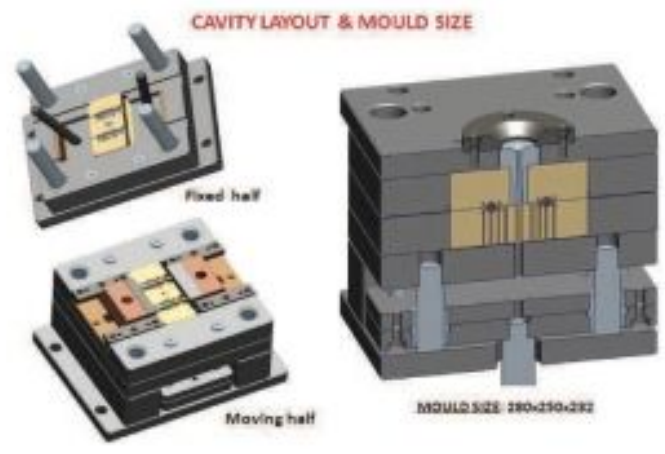

Figure 15, Cavity layout and mold size

\section{Conclusions}

Plastic advisor 7.0 has given the results for the best gate location, confidence of fill, quality, weld lines and air traps. Weld lines and air traps which are appeared in the analysis can be overcome by changing the process parameter related to speed and pressure during production. Instead of water different types of oils can be used for effective cooling of the die. Thermal and stress analysis can be performed over the die by using ANSYS.

\section{REFERENCES}

[1] Castro, C.E, Rios, M.C, B.L and M.C.J (2005) "Simultaneous Optimization of Mold Design and processing Conditions in Injection molding ", Journal of Polymer Engineering, 25(6), 459-486.

[2] Jitendra Dilip Ganeshkar, Prof. R.B. Patil, Swapnil S. Kulkarni, "Design of plastic injection mold for an automotive component through flow analysis (CAE) for design enhancement". International journal of Engineering research and studies, Jan 2014, E-ISSN2249-8974.

[3] Alireza Akbarzadeh, Mohammad Sadegi, "Parameter study in plastic Injection Molding process using Statistical Methods and IWO Algorithm", International joumal of modeling and optimization, Vol.1, No. 2, June 2011.

[4] Nik Mizamzul Mehat, Shahrul Kamaruddin, Abdul Rahim Othman, "Modeling and Analysis of Injection Molding Process parameters for Plastic Gear Industry Application", ISRN Industrial Engineering Vol 13 Article ID 869736, 2013

[5] CITD, Die Design Handbook. 1980. Company standards book, "Mold master data hand book", 2003. 